\title{
Habit reversal improvement in the fish'
}

RONALD G. SETTERINGTON ${ }^{2}$ AND HARDING E. BISHOP

UNIVERSITY OF TORONTO

Seven African mouthbreeder fish were given 80 reversals of a position discrimination in a target pressing situation. Contrary to earlier successive reversal studies with the fish a progressive between-reversals improvement occurred over the 80 reversals. Methodological differences likely contributing to the difference in results between earlier studies and the present study were discussed.

Past experiments with the fish have found no indication of the progressive improvement over successive habit reversals so easily demonstrated in the pigeon, rat, and monkey (Bitterman, 1965).

The African mouthbreeder fish studied by Bitterman, Wodinsky, \& Candland (1958) showed no improvement in either initial errors or repetitive errors when given successive reversals of simple visual and spatial problems in a two-alternative target pressing situation. Both a limited correction procedure and a noncorrection with guidance procedure produced negative results, and it made little difference whether reversals occurred after a set number of trials or after the attainment of a criterion performance. A later study by Behrend, Domesick, \& Bitterman (1965), also using the target pressing response, found no improvement in either the African mouthbreeder or the goldfish over as many as 168 reversals of visual, spatial, visual-spatial confounded, and Riopelle problems. Paradise fish have also failed to improve over successive reversals of a visual-spatial confounded problem when tested in a $\mathrm{T}$-maze (Warren, 1960).

While investigating place learning set-a series of spatial rather than the usual visual problems (Bishop, 1965)-in the African mouthbreeder fish, the present authors developed a method of producing improvement in repetitive errors which was applicable to the successive habit reversal situation. The main features of this method involved the use of small targets far enough apart to provide clearly distinguishable position cues, and an unlimited correction procedure in which the manipulanda (targets) were briefly withdrawn from the experimental enclosure following each incorrect response. It was expected that progressive improvement would occur in the African mouthbreeder, at least in the repetitive errors measure, when these features were incorporated into a successive habit reversal experiment.

\section{Method}

Subjects. Seven adult African mouthbreeder fish (Tilapia macrocephala), male and female, 2 to $3-1 / 4$ in. in length were obtained from a local tropical fish breeder. Each $\mathrm{S}$ was housed in a glass tank 12 in. $x$ 6 in. $x 8$ in. high. Tank heaters maintained a temperature of $78^{\circ} \mathrm{F}$ while filters continuously aerated and cleaned the water. For several weeks prior to reversal training Ss had been adjusting to a $16 \mathrm{hr}$. light$8 \mathrm{hr}$. dark cycle and a deprivation schedule of $.05 \mathrm{gm}$ dried food given every $24 \mathrm{hr}$. Throughout training the same light-dark cycle was maintained and Ss continued to receive $.05 \mathrm{gm}$ dried food, approximately $1 / 2 \mathrm{hr}$. after the training session ended, at the same time each day.

Apparatus and Pretraining. During each training session a snugly fitting plywood box, from which targets could be manually lowered into the water, was placed over S's tank. A 4-w daylight fluorescent tube situated 2 in. above the water at one end of the tank provided illumination within the apparatus. An observation window $4-3 / 4$ in. wide and 4 in. high at the same end of the tank as the fluorescent tube allowed observation of S during training; darkening the experimental room prevented $S$ from seeing outside the apparatus. The two identical targets were white plastic beads $1 / 4 \mathrm{in}$. in diameter attached to light metal rods which hung from a movable platform (Hogan \& Rozin, 1962). When lowered into operating position the targets were side by side $3-3 / 4 \mathrm{in}$. apart, $3 / 4 \mathrm{in}$. from the end of the tank opposite the observation window, and $1 \mathrm{in}$. below the surface of the water. A 1/8-in. movement of the targets was sufficient to close an electrical contact which operated a recorder and controlled the reinforcement contingencies. The inside of the apparatus was white except for a small black area immediately beyond the targets as $\mathrm{S}$ approached them. Reward was a single white worm (Enchytraeus albidus) squirted into the water from above as the bulb of an eye dropper containing the worm was squeezed by a solenoid.

Ss were pretrained to press a single target through the method of successive approximation. Five consistently rewarded trials were given a couple of seconds apart during each of the first five daily sessions with the reward location near the target. During the further 24 daily sessions of pretraining each $\mathrm{S}$ received 10 massed, consistently rewarded trials; reward was presented in the center of the tank 4 in. behind $S$ as the target was being pressed during these 240 additional pretraining trials and throughout reversal training. The left-right location of the single target during pretraining varied randomly from session to session ensuring equal strength of response to both target locations.

Reversal Training. On the first day of reversal training Ss received an initial left-right position discrimination in which the correct target was randomly selected for each S. On each of days 2 to 81 of reversal training each $\mathrm{S}$ received one reversal with the correct 


\section{Results and Discussion}

In order to determine whether the shock box treatment on day 7 had affected the Ss' subsequent runway performance prior to the introduction of shock into the runway a Kruskal-Wallis nonparametric one-way analysis of variance was performed on the time taken to traverse the runway and begin eating (consummatory latency) on the first trial as a function of the stimulation administered in the shock box (High shock, Low shock, or No shock). A significant Chi square was obtained (Chi square $=25.93, \mathrm{df}=2, \mathrm{p}<.001)^{2}$ and further analysis with Mann-Whitney U tests showed that the group of animals receiving intense shock in the shock box had significantly longer consummatory latencies than did either the Low shock $(p<.01)$ or the No shock group $(p<.01)$ while the difference between the Low shock and No shock groups was not significant $(p>.2)$. This indicates that in spite of the attempt to reduce the similarity between the shock and test apparatus, stimulus generalization probably occurred. While the stimulus situation was considerably different in the two situations, there were factors which could act as a source for stimulus generalization. Perhaps the most obvious stimuli are those associated with the experimenter, such as being handled, and all the stimuli associated with this procedure. While other studies have not found stimulus generalization effects, this may be due to their long delay between the shock box stimulation and approach training.

A Kruskal-Wallis nonparametric one-way analysis of variance of the consummatory latencies on trial 22 (the last trial of approach training before the introduction of electric shock into the runway) as a function of the three shock box stimulation conditions yielded an insignificant Chi square (Chi square $=4.79, \mathrm{df}=2, \mathrm{p}>$ $.05)$. This indicates that by the time electric shock was introduced into the runway the approach strengths of the animals did not differ significantly as a function of the treatment received in the shock box.

Since all the Ss tested with $.80 \mathrm{ma}$ shock in the runway stopped consuming by the 25th trial, analysis of the differences between the $\mathrm{HH}$ and $\mathrm{NH}$ groups was limited to the reconsummatory latencies on trial 23 and the consummatory latencies on trial 24. Mann-Whitney $\mathrm{U}$ tests of the difference between the $\mathrm{HH}$ and $\mathrm{NH}$ groups on these two measures were significant at the .05 level in both cases with the HH group having longer consummatory and reconsummatory latencies than the $\mathrm{NH}$ group. The median consummatory latencies for the $\mathrm{NH}$ and $\mathrm{HH}$ groups on trial 24 were 11.2 sec. and
46.5 sec., respectively, while the median reconsummatory latencies on trial 23 were $45.6 \mathrm{sec}$. and 168.8 sec., respectively.

Since all the Ss tested with .25 ma shock made consummatory responses throughout avoidance training, a median consummatory latency was obtained for each $S$ for trials 24-27, and a Mann-Whitney $U$ test was performed on the difference between the NL and $L L$ groups. The difference between these groups was significant at the .05 level, with the NL group (Median= $1.6 \mathrm{sec}$ ) having significantly lower consummatory latencies than the LL group (Median=2.3 sec.). A similar analysis of the differences between the median reconsummatory latencies for trials $23-27$ for these two groups was significant at the .02 level with the LL group (Median $=6.4$ sec.) taking significantly longer time to return to the food and begin eating than the NL group (Median=less than 1 sec.).

The results of this experiment are in agreement with the results of the studies by Kurtz and his associates and extend the findings to low as well as high levels of shock. The results are contrary to the hypothesis of adaptation to mild shock and raise the question of whether intense fear is necessary to produce sensitization to aversive stimulation. Kurtz has hypothesized that intense fear experiences produce the effect, but it is difficult to consider .25 ma shock as a stimulus which produces intense fear since the administration of this shock in the shock box rarely evoked a clearly observable sign of emotional behavior such as vocalization or defecation.

\section{References}

Denenberg, V. Early experience and emotional development. Scient. American. 1963, 208, 138-146.

Kurtz, K., \& Walters, G. The effects of prior fear experiences on an approach-avoidance conflict. J. comp. physiol. Psychol., $1962,55,1075-1078$.

Miller, N. E. Learning resistance to pain and fear: effects of overlearning, exposure and rewarded exposure in context. J. exp. Psychol., 1961, 60, 137-145.

Pearl, J., Walters, G., \& Anderson, D. Suppressing effects of aversive stimulation on subsequently punished behavior. Canad. $J$. Psychol., 1964, 18, 343-355.

Steckle, L., \& $\mathbf{O}^{\prime}$ Kelley, L. Persistence of response as a function of thirst in terms of early experience with electric shock. $J$. comp. Psychol., 1941, 32, 1-9.

Walters, G., \& Rogers, J. V. Aversive stimulation of the rat: longterm effects on subsequent behavior. Science, 1963, 142, 70-71.

\section{Notes}

1. Present address: Department of Psychology, University of Oklahoma, Norman, Oklahoma.

2. All probability statements are based upon two-tailed tests. 